\title{
PERBANDINGAN MODEL PEMBELAJARAN ELABORASI DENGAN MODEL PEMBELAJARAN ADVANCE ORGANIZER
}

\author{
Andy Sapta \\ Dosen Matematika, STMIK Royal, Kisaran, Sumatera Utara \\ e-mail : sapta@royal.ac.id
}

\begin{abstract}
Abstrak. Penelitian ini bertujuan untuk mengetahui perbandingan hasil belajar matematika siswa yang menggunakan model pembelajaran Elaborasi dengan hasil belajar yang menggunakan model pembelajaran Advance Organizer pada materi fungsi di kelas XI IPA SMA Negeri 1 Buntu Pane. Populasi dalam penelitian ini adalah semua siswa kelas XI IPA SMA Negeri 1 Buntu Pane. Sampel penelitian ini diambil 2 kelas dengan teknik claster random sampling. Alat pengumpul data digunakan tes hasil belajar siswa pada materi Fungsi dalam bentuk pilihan ganda yang terdiri dari 10 soal. Dari analisa data diperoleh nilai rata-rata pretes dengan model pembelajaran Elaborasi sebesar 67,61 dengan nilai rata-rata postes 80,55. Sedangkan untuk kelas dengan model pembelajaran Advance Organizer diperoleh nilai rata-rata pretes sebesar 69,05 dengan nilai rata-rata postes 74,61. Dari uji hipotesis yang dilakukan dengan menggunakan uji satu pihak didapat bahwa $H_{O}$ ditolak. Dengan demikian dapat disimpulkan bahwa hasil belajar matematika pada materi fungsi yang menggunakan model elaborasi lebih baik daripada menggunakan model Advance Organizer pada siswa kelas XI IPA SMA Negeri 1 Buntu Pane.
\end{abstract}

Kata kunci: model Elaborasi, model Advance Organizer, Fungsi

\begin{abstract}
This study aims to determine the comparison of mathematics learning outcomes of students who use Elaboration learning model with learning outcomes that use Advance Organizer learning model on the material function in class XI IPA SMA Negeri 1 Buntu Pane. Population in this research is all student of class XI IPA SMA Negeri 1 Buntu Pane. The sample of this research is taken two class with cluster random sampling technique. Data collection tool used test result of student learning on material Function in the form of multiple choice consist of ten problem. From the data analysis, the average value of pretest with Elaboration learning model is 67.61 with the average value of postest 80.55. As for the class with the learning model of Advance Organizer obtained pretest average value of 69.05 with the average postest 74.61 . From the hypothesis test conducted by using one party test found that rejected. Thus it can be concluded that the results of mathematics learning on the material functions that use the elaboration model is better than using the Advance Organizer model on the students of grade XI IPA SMA Negeri 1 Buntu Pane.
\end{abstract}

Keywords: Elaboration model, Advance Organizer model, Function

\section{PENDAHULUAN}

Matematika sebagai salah satu ilmu dasar yang tidak dapat dipisahkan dari perkembangan ilmu pengetahuan dan teknologi. Oleh karena itu, apabila matematika tidak dikuasai dengan baik, maka mutu kegiatan keilmuan tidak mencapai taraf yang memuaskan. Namun kenyataannya, masih banyak siswa yang belum dapat mencapai hasil belajar matematika yang diharapkan. Salah satu faktor penyebabnya adalah kurang tepatnya model pembelajaran yang digunakan di sekolah, seperti dinyatakan oleh Yansen (dalam Uno, 2012) bahwa pembelajaran mata pelajaran matematika di Indonesia masih lemah. Pengajaran terfokus pada teori sehingga murid menjadi kurang kreatif, terlalu formal dan masih terpaku pada rumus yang baku.

Secara umum tugas guru matematika diantaranya adalah: pertama, bagaimana materi pelajaran itu diberikan kepada siswa sesuai dengan standar kurikulum. Kedua, bagaimana proses pembelajaran berlangsung melibatkan peran siswa secara penuh dan aktif. Pada tahap ini, guru harus menetapkan model pembelajaran yang efektif dimana memiliki nilai relevansi 
dengan pencapaian daya matematika dan memberi peluang untuk bangkitnya kreativitas guru, kemudian berpotensi mengembangkan suasana belajar mandiri yang dapat menarik perhatian siswa.

Salah satu model pembelajaran yang melibatkan siswa menjadi lebih aktif adalah pembelajaran yang menggunakan penstrukturan isi pelajaran yang akan disajikan. Dikarenakan matematika sebagai ilmu yang tersusun menurut struktur maka sajian matematika hendaknya dilakukan secara sistematis dan logis sesuai perkembangan intelektual anak. Dengan cara seperti ini siswa yang belajar akan siap menerima pelajaran dilihat dari segi perkembangan intelektualnya.

Pembelajaran dengan model elaborasi dan model Advance Organizer merupakan pembelajaran yang menggunakan penstrukturan isi pelajaran yang disajikan. Model elaborasi yang merupakan penyajian pembelajaran dengan mengorganisasikan materi pelajaran melalui 7 langkah antara lain: rangkaian elaborative, urutan prasyarat belajar, membuat ringkasan, sintesa, analogi, dan aktivator strategi kognitif serta kontrol belajar. Model Advance Organizer yang merupakan penyajian pembelajaran melalui 3 langkah antara lain: presentase, pengorganisasian, presentase tentang tugas mengajar dan memperkuat organisasi berpikir siswa. Penstrukturan suatu materi pelajaran membutuhkan suatu model. Melalui model pengorganisasian dan penyampaian pelajaran yang optimal akan memberikan daya tarik siswa untuk mempelajari suatu bidang study, sehingga akan tercapai tujuan pengajaran yang diinginkan. Dengan kata lain, guru memberikan kemudahan pada siswa dalam belajar melalui model pembelajaran yang cocok dengan materi yang disajikan. Hal ini sesuai dengan pendapat Degeng (dalam Uno, 2012) menyatakan bahwa bahan ajar yang diorganisasikan dengan baik lebih mudah untuk dipelajari daripada yang tidak diorganisasikan dengan baik. Suatu alternatif penggunaan model pembelajaran untuk mencapai tujuan pembelajaran adalah dengan model elaborasi. Model elaborasi merupakan cara mengorganisasikan pengajaran dengan mengikuti urutan dari umum ke rinci yang dimulai dengan menampilkan struktur isi bidang studi yang akan dipelajari di awal pelajaran.

Dari hasil pengamatan yang terdapat pada siswa kelas XI IPA SMA Negeri 1 Buntu Pane melalui percakapan wawancara lisan bahwa materi fungsi merupakan materi yang dianggap sulit hal ini juga didukung oleh rendahnya hasil belajar siswa pada materi tersebut. Salah satu penyebabnya adalah kurangnya penguasaan siswa akan konsep fungsi.

\section{METODE}

Metode dalam penelitian ini adalah kuantitatif berbentuk quasi eksperiment. Dalam penelitian ini diuji suatu perlakuan untuk mengetahui hubungan antara perlakuan dengan aspek tertentu yang diukur. Perlakuan yang diberikan adalah pembelajaran matematika dengan menggunakan model pembelajaran Elaborasi dan model pembelajaran Advance Organizer.

Penelitian ini dilaksanakan di SMA Negeri 1 Buntu Pane, kabupaten Asahan, provinsi Sumatera Utara. Waktu penelitian dilaksanakan pada semester ganjil Tahun Ajaran 2015/2016. Populasi penelitian ini adalah kelas XI IPA SMA Negeri 1 Buntu Pane yang berjumlah 114 orang. Sampel yang terdiri dari dua kelas meliputi satu kelas eksperimen 1 (model pembelajaran Elaborasi) dan satu kelas eksperimen 2 (model pembelajaran Advance Organizer). Sampel penelitian ini terdiri dari 56 siswa. Penentuan kedua kelas eksperimen dengan cara teknik claster random sampling. Untuk melihat kelayakan sampel dari kedua kelas, terlebih dahulu dilakukan uji persyaratan data yang meliputi uji normalitas dan uji homogenitas.

Sumber data dari penelitian ini diambil dari sumber data primer dan skunder. Sumber data skunder diperoleh melalui wawancara guru dan kepala sekolah serta pegawai untuk memperoleh informasi mengenai hasil belajar siswa, kelas, kondisi sekolah dan strategi 
mengajar guru serta dokumen-dokumen lain yang mendukung. Sedangkan sumber data primer diperoleh melalui tes hasil belajar siswa pada materi fungsi.

Tes yang digunakan adalah tes pilihan berganda. Tes hasil belajar yang digunakan adalah soal pilihan berganda yang direncanakan terdiri dari 10 butir soal. Waktu mengerjakan tiap butir soal adalah 3 menit. Soal pretest dan postest yang diberikan atau diujikan terhadap kelompok eksperimen 1 dan kelompok eksperimen 2 adalah sama. Sebelum soal digunakan terlebih dahulu dilihat karakteristik soal tersebut antara lain: validitas tes, reabilitas tes, daya pembeda tes, dan tingkat kesukaran.

Dalam penelitian data yang diolah adalah hasil belajar siswa dari kelas sampel setelah data dari kelas sampel diperoleh, maka dilakukan langkah-langkah sebagai berikut: uji normalitas, uji homogenitas, dan uji hipotesis.

\section{HASIL DAN PEMBAHASAN}

Dari hasil penelitian, hasil pretes siswa kelas Eksperimen 1 (Elaborasi) dan kelas Eksperimen 2 (Advance Organizer) dalam rentang nilai 0 - 100 diperoleh bahwa nilai ratarata pretes kelas Eksperimen 1 adalah 67,61 dengan simpangan baku 6,96 sedangkan nilai pretes kelas Eksperimen 2 adalah 69,05 dengan simpangan baku 8,03. Perbandingan nilai pretes antar kedua kelas tidak berbeda signifikan.

Setelah diterapkan model pembelajaran Elaborasi diperoleh bahwa nilai rata-rata postes kelas Eksperimen 1 adalah 80,55 dengan simpangan baku 8,15. Sedangkan pada kelas Eksperimen 2 yang menggunakan model pembelajaran Advance Organizer adalah 74,61 dengan simpangan baku 7,65.

Tabel 1. Hasil Pretes dan Postes Pada Kelas Eksperimen

\begin{tabular}{ccccc}
\hline & \multicolumn{2}{c}{ PRETES } & \multicolumn{2}{c}{ POSTES } \\
\cline { 2 - 5 } & $\begin{array}{c}\text { NILAI RATA- } \\
\text { RATA }\end{array}$ & $\begin{array}{c}\text { SIMPANGAN } \\
\text { BAKU }\end{array}$ & $\begin{array}{c}\text { NILAI } \\
\text { RATA-RATA }\end{array}$ & $\begin{array}{c}\text { SIMPANGAN } \\
\text { BAKU }\end{array}$ \\
\hline $\begin{array}{c}\text { MODEL } \\
\text { PEMBELAJARAN } \\
\text { ELABORASI }\end{array}$ & 67,61 & 6,95 & 80,55 & 8,15 \\
\hline $\begin{array}{c}\text { MODEL } \\
\text { PEMBELAJARAN } \\
\text { ADVANCE }\end{array}$ & 69,05 & 8,03 & 74,61 & 7,65 \\
ORGANIZER & & & & \\
\hline
\end{tabular}

Uji persyaratan analisa data meliputi uji normalitas dan uji homogenitas data pretes dan data postes siswa kelas Eksperimen 1 dan kelas Eksperimen 2. Uji normalitas menggunakan uji liliefors. Hasil uji normalitas tertera pada tabel 2.

Tabel 2. Hasil Uji Normalitas Data

\begin{tabular}{cccccc}
\hline No & Data & Kelas & $L_{\text {hitung }}$ & $L_{\text {tabel }}(\alpha=0,05)$ & Keterangan \\
\hline \multirow{2}{*}{1.} & \multirow{2}{*}{ Pretes } & Eksperimen 1 & 0,0895 & 0,1610 & Normal \\
\cline { 3 - 6 } & \multirow{2}{*}{2.} & Eksperimen 2 & 0,0572 & 0,1610 & Normal \\
\hline \multirow{2}{*}{ Postes } & Eksperimen 1 & 0,1252 & 0,1610 & Normal \\
\cline { 3 - 6 } & & Eksperimen 2 & 0,0832 & 0,1610 & Normal \\
\hline
\end{tabular}

Pengujian homogenitas dilakukan dengan menggunakan uji $F$. Secara ringkas hasil uji homogenitas data tertera dalam tabel 3. 
Tabel 3. Hasil Uji Homogenitas Data

\begin{tabular}{|c|c|c|c|c|c|c|}
\hline No & Data & Kelas & Varians & $F_{\text {hitung }}$ & $\mathrm{F}_{\text {tabel }}$ & Keterangan \\
\hline \multirow{2}{*}{1.} & \multirow{2}{*}{ Pretes } & Eksperimen 1 & 48,39 & \multirow{2}{*}{1,45} & \multirow{2}{*}{1,84} & \multirow{2}{*}{ Homogen } \\
\hline & & Eksperimen 2 & 70,32 & & & \\
\hline \multirow{2}{*}{2.} & \multirow{2}{*}{ Postes } & Eksperimen 1 & 74,20 & \multirow{2}{*}{1,38} & \multirow{2}{*}{1,84} & \multirow{2}{*}{ Homogen } \\
\hline & & Eksperimen 2 & 53,70 & & & \\
\hline
\end{tabular}

Tabel 4. Uji Hipotesis

\begin{tabular}{ccccc}
\hline No & Tes & $\mathrm{t}_{\text {hitung }}$ & $\mathrm{t}_{\text {tabel }}$ & Keterangan \\
\hline 1. & Pretes & 0,65 & 1,67 & \multirow{2}{*}{$H_{o}$ ditolak } \\
\hline 2. & Postes & 3,27 & 2,00 & \\
\hline
\end{tabular}

Pengujian hipotesis ditentukan dengan melihat perbandingan kedua kelas dengan berbeda model pembelajaran. Nilai rata-rata pretes siswa kelas Eksperimen 1 adalah 70,53 dan kelas Eksperimen 2 adalah 69,23. Dari hasil perhitungan diperoleh $t_{\text {hitung }}=0,65$ dan $t_{\text {tabel }}$ untuk $\alpha=0,05$ adalah 1,67. Karena $t_{\text {hitung }}<t_{\text {tabel }}$ dapat dinyatakan bahwa tidak ada perbedaan kemampuan awal antara siswa kelas Eksperimen 1 dan kelas Eksperimen 2.

Nilai rata-rata postes siswa kelas Eksperimen 1 adalah 81,73 dan kelas Eksperimen 2 adalah 76,53. Dari hasil perhitungan diperoleh $t_{\text {hitung }}=3,27$ dan $t_{\text {tabel }}$ untuk $\alpha=0,05$ adalah 2,00. Karena $t>t_{(1-\alpha)}=3,27>2,00$ berarti model pembelajaran Elaborasi lebih baik daripada model pembelajaran Advance Organizer pada materi fungsi di kelas XI IPA SMA Negeri 1 Buntu Pane.

\section{Pembahasan}

Penelitian yang dilakukan di SMA Negeri 1 Buntu Pane dan ini melibatkan dua kelas yaitu kelas Eksperimen 1 dan kelas Eksperimen 2. Sebelum diberi perlakuan kedua kelas diberi pretest untuk mengetahui kemampuan awal siswa. Berdasarkan pengujian yang dilakukan diperoleh bahwa kedua kelas homogenya dan berdistribusi normal.

Uji $t$ yang dipakai pada pretest siswa kelas Eksperimen 1 dan kelas Eksperimen 2 yaitu uji $t$ kesamaan dua rata-rata, yang digunakan untuk mengetahui apakah ada kesamaan atau ada perbedaan kemampuan awal antara siswa kelas Eksperimen 1 dan kelas Eksperimen 2. Dari hasil perhitungan diperoleh bahwa tidak terdapat perbedaan yang signifikan antara siswa kelas Eksperimen 1 dan kelas Eksperimen 2, ini berarti bahwa kemampuan awal siswa antara kelas Eksperimen 1 dan kelas Eksperimen 2 sama sebelum diberi perlakuan.

Setelah melakukan pretest kemudian kedua kelas diberi perlakuan yang berbeda. Dari penelitian yang dilakukan dengan menggunakan model pembelajaran Elaborasi dan Advance Organizer, namun ada kendala-kendala yang ditemukan saat di lapangan dan hal ini mempengaruhi proses belajar mengajar, seperti: (1) Pembelajaran dengan menggunakan model pembelajaran Elaborasi dan Advance Organizer membutuhkan waktu yang relatif lama sedangkan waktu yang ada sangat terbatas; (2) Adanya faktor-faktor ekstern yang mempengaruhi selama proses belajar mengajar seperti lingkungan sekolah yang kurang kondusif. Tidak bisa selamanya guru berlaku manis, baik dan perhatian kepada siswa. Justru sikap ini bisa diremehkan siswa. Jadi guru dalam hal ini harus lengkap perangainya bisa marah, namun juga bisa ramah; (3) Pada lembar jawaban terdapat kurang kepercayaan diri siswa dalam menyelesaikan soal, hal ini dapat dilihat dari jawaban pertama sudah benar tetapi dihapusnya dan diganti dengan jawaban yang salah.

Setelah diberi perlakuan yang berbeda siswa kelas Eksperimen 1 dan kelas Eksperimen 2, kemudian kedua kelas diberi postest atau postest untuk mengetahui kemampuan akhir siswa dari siswa kelas Eksperimen 1 dan kelas Eksperimen 2. Dari 
pengujian yang dilakukan melalui postest yang diberikan diperoleh bahwa kedua kelas homogen dan berdistribusi normal.

Uji $t$ yang digunakan pada postes yaitu uji $t$ satu pihak, dimana uji satu pihak dilakukan untuk melihat bahwa model pembelajaran Elaborasi lebih baik dari model pembelajaranAdvance Organizer yang diterapkan pada materi fungsi pada siswa kelas Eksperimen 1 dan kelas Eksperimen 2. Dari pengujian yang dilakukan diperoleh bahwa nilai rata-rata postes siswa kelas Eksperimen 1 lebih baik dari kelas Eksperimen 2, dan dari analisa data yang dilakukan bahwa dapat disimpulkan hasil belajar matematika pada materi fungsi yang menggunakan model elaborasi lebih baik daripada menggunakan model Advance Organizer pada siswa kelas XI IPA SMA Negeri 1 Buntu Pane.

\section{PENUTUP}

\section{Kesimpulan}

Keimpulan yang dapat diambil dari hasil penelitian ini adalah sebagai berikut:

1. Hasil belajar siswa menggunakan model pembelajaran Elaborasi pada materi Fungsi di kelas XI IPA SMA Negeri 1 Buntu Pane diperoleh nilai rata-rata pretes 67,61 dan postes 80,55

2. Hasil belajar siswa menggunakan model pembelajaran Advance Organizer pada materi Fungsi di kelas XI IPA SMA Negeri 1 Buntu Pane diperoleh nilai rata-rata pretes 69,05 dan postes 74,61

3. Model pembelajaran Elaborasi lebih baik daripada model pembelajaran Advance Organizer pada materi Fungsi di kelas XI IPA SMA Negeri 1 Buntu Pane.

\section{Saran}

Dari hasil penelitian dapat diajukan saran sebagai berikut:

1. Dalam melakukan model pembelajaran Elaborasi dan pembelajaran Advance Organizer sebaiknya dapat lebih memperhatikan lagi lingkungan di sekitar sekolah yang mendukung proses pembelajaran tersebut yaitu lingkungan yang kondusif dan guru dapat memotivasi kepercayaan diri siswa dalam menjawab soal, agar hasil yang diharapkan lebih baik lagi

2. Dalam merancang kegiatan pada rencana pelaksanaan pembelajaran agar lebih diperhatikan lagi sehingga dapat terlaksana dengan baik dan sesuai dengan yang ingin dicapai.

\section{DAFTAR PUSTAKA}

Ansari, B.I. 2012. Komunikasi Matematis dan Politik Suatu Perbandingan: Konsep dan Aplikasi. Banda Aceh: PeNA.

Arikunto, 2013. Prosedur Penelitian.Jakarta: Rineka Cipta.

Fathoni, A. 2007. Bahasa Matematikahttp://rbaryans.worpress.com/2007/05/30/komunikasidalam- matematika.html. diakses 9 September 2012.

Purba, O. N. 2016. Peningkatan Kemampuan Komunikasi Matematika Siswa Menggunakan Pembelajaran Berbasis Lingkungan. Jurnal Mathematics Paedagogic. VII (1): 19 - 28

Sapta, A. 2016. Publication of The Assessment Learning Outcomes Through Social Media. The $1^{\text {st }}$ Annual International Seminar on Transformative Education and Educational Leadership. $480-483$

Sapta, A., \& Marchi, R. F. The Development of Modelling The Way Learning In The Course of The Mathematics Curriculum of Junior High School.

Uno, H.B. 2012. Model Pembelajaran. Jakarta: Bumi Aksara 
Vol. 5, No. 1 Hal 9 - 13

ISSN (Print): 2337-6198

Januari - Juni 2017

ISSN (Online): 2337-618X 